\title{
Protecting University Students From Bullying And Harassment: A Review Of The Initiatives At Canadian Universities
}

\author{
Magdalena Cismaru, University of Regina, Canada
}

Romulus Cismaru, University of Regina, Canada

\begin{abstract}
Students' bullying and harassment have been shown to be a problem and more schools around the world are starting to address them. Although much of the attention and research has focused on middle-school students, addressing bullying and harassment in universities is important and makes the object of the present research. We provide an overview of how student versus student bullying and harassment are reported, monitored, and dealt with at Canadian educational institutions. Specifically, we identify schools where there is information and policies regarding students' persecution; we describe how colleges help and what advice they offer; we discuss frameworks used to tackle it; as well, we present other initiatives aiming to prevent it. We also attempt to evaluate measures by linking them with incidence figures. This review may guide future initiatives to tackle intimidation with the ultimate goal of improving the quality of university environment.
\end{abstract}

Keywords: Bullying; Harassment; University Students; Canada

\section{INTRODUCTION}

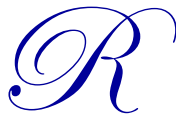

etention of students through improving the quality of university experience has long been a central issue for universities (Murtaugh, Burns, \& Schuster, 1999). Understanding the patterns of student retention is not easy and there is considerable room for improvement (Nandeshwar, Menzies, \& Nelson, 2011; Johnson, 2001). Going to university is a period of big changes characterized by significant stress levels. Some of the stressors associated with going to university might be: academic workload, the need to live away from home for the first time, lack of family support, changes in the social life (meeting new people, making new friends), cultural differences (language barrier, moving from a rural community to an urban one), sexual and intellectual jealousy, discrimination, and bullying and harassment (Karim, 2010; Zimbroff, 2007).

Literature shows numerous definitions for bullying and harassment. As defined by the Norwegian researcher Dan Olweus (1996, p.265) in the late 1970's, bullying occurs when "a student...is exposed, repeatedly and over time, to negative actions on the part of one or more other students". More recent definitions (Colorosa, 2008) mention three main elements of bullying: the imbalance of power (Canadian Red Cross, 2016), the intent to harm, and the threat to further aggression. Bullying can be physical (e.g., hitting), verbal (e.g., name-calling), social/relational (e.g., gossiping), and cyber (e.g., sending threatening text messages) (Canadian Red Cross, 2016; Wang, Iannotti, \& Nansel, 2009). Bullying and harassment have similarities and differences. Indeed, while harassment is similar to bullying because someone hurts another person through cruel, offensive and insulting behaviors, it is also different from bullying in that it is a form of discrimination (based on age, race, ethnicity, religion, sex, sexual orientation, family status, marital status, physical and mental disability) (Canadian Red Cross, 2016).

Victims of such intimidation often do not report it. A survey of 2805 Finnish college students reveal around 5\% of students reported being bullied either by a fellow student or by a member of staff (Lappalainen, Meriläinen, Puhakka, \& Sinkkonen, , 2011). Nevertheless, victims of persecution do not often report it due to: embarrassment, inability to self-admit, lack of confidence in the system (Brank, Hoetger, \& Hazen, 2012; Greengrass, 2013; Karim, 2010), and different points of view of what bullying is (Brank et al., 2012). Indeed, in multicultural environments that are quite 
widespread in colleges due to globalization, complex and controversial issues may occur due to culturally-derived values and beliefs that may determine when and what specific behaviors and feelings are appropriate and when they are not (Zimbroff, 2007). Also, cyber bullying has the potential of reaching students from all cultures. Student bullies use social media platforms, e-mail, mobile phone, and text messages to harass, abuse, and scare others (Greengrass, 2013). As well, sexual harassment among university students is prevalent and underreported (Telegraph, 2015a). In a series of articles, it was demonstrated that although a third of female students in Britain have endured a sexual assault or unwanted advances in college, $97 \%$ did not report it to the school, because they did not think the university would act in any way (Telegraph, 2015b).

Evidence shows that individuals that are bullied or harassed may suffer numerous short and long-term negative consequences (Brank et al., 2012). They include alcohol and drug abuse, eating disorders (Greengrass, 2013), damage to self-esteem, issues with academic achievement, problems regarding emotional and physical wellbeing (Brank et al, 2012; Cowie \& Myers, 2014), depression (Aricak, 2009), anxiety, and paranoia (Schenk \& Fremouw, 2012). Bullied and harassed students may interrupt their studies (Sinkkonen, Puhakka, \& Merilainen, 2014), dramatically impacting their future.

Due to the numerous and potential severe consequences of bullying and harassment, educational institutions implemented policies and educational and legal interventions (Brank et al., 2012). Policies on persecution provide a roadmap for the schools to address these issues in a consistent and fair way and at the same time making it clear of what is expected from everyone to be safe and legal (Canadian Red Cross, 2016). Such policies often cover six key elements: purpose, scope and application of the policy, standard of behavior, procedures for receiving and reviewing complaints, reporting systems and framework, disciplinary sanctions and appeal mechanism (Canadian Red Cross, 2016).

Several educational program models such as: Olweus model (Stevens, De Bourdeaudhuij, \& Van Oost, 2000).), BullyProofing your School (BPYS), Promoting Alternative Thinking Strategies (PATHS) Curriculum, Second Step, Steps to Respect, Safe School Ambassadors, Beyond the Hurt have been developed to tackle the issue of bullying (Bullying Prevention Resources Guide, 2013; Canadian Red Cross, 2016). They use a variety of tools to help preventing intimidation. For example, Beyond the Hurt offers an online course, workshops, facilitator training, and curriculum alignment (Canadian Red Cross, 2016).

The legal landscape surrounding bullying is changing rapidly. The vast literature on school bullying (Cowie \& Myers, 2014) led to changes in legislation in the US. Indeed, most US states have enacted legislation prohibiting oppression behaviors and requiring school districts to adopt policies regarding bullying (Brank et al., 2012; Sacco, Silbaugh, Corredor, \& Doherty, 2012). In Australia, recognition of bullying varies from jurisdiction to jurisdiction (Bullying Laws in Australia, 2014). In Canada, at the national level, many behaviors or episodes characterized as bullying fit the definition of criminal offenses (i.e., criminal harassment, uttering threats, assault, and sexual assault) (Panjvani, 2013). Provinces use different approaches and only some have anti-bullying legislation in place (Panjvani, 2013). Examples include The Public Schools Act in Manitoba, the Promotion of Respectful and Responsible Relationships Act in Nova Scotia, the Education Act in New Brunswick, Ontario, and Alberta, the Education Act and the Act Respecting Private Education in Quebec (Panjvani, 2013). Most of the other provinces and territories have some strategies to address persecution. Examples include British Columbia's ERASE Bullying (Expect Respect and a Safe Education) strategy, Saskatchewan's Caring and Respectful Schools initiative, Yukon's Safe and Caring Schools Policy, Newfoundland and Labrador's Safe and Caring Schools Policy.

A recent paper by Cowie and Myers (2014) emphasizes that the study of bullying at the university level is underresearched and needs attention. Therefore, our research has the following objectives:

\section{OBJECTIVES}

1. To review anti-bullying and anti-harassment information/policies existing at Canadian Universities.

2. To specify what kind of advice and help colleges offer to students that are in a bullying or harassment circumstance (victims of persecution, friends or colleagues of someone who is bullied, or individuals that simply want to contribute to an anti-intimidation environment). 
3. To present theoretical frameworks or models aiming to tackle oppression.

4. To review and describe any other initiatives intending to tackle bullying at Canadian colleges.

5. To evaluate the effectiveness of specific preventing measures by linking them to incidence figures.

\section{METHODOLOGY}

This study involved conducting an extensive Internet search of materials and articles regarding bullying and harassment concerning college students. Most of the information was obtained from the universities' websites and academic articles found in databases such as, ABI/Inform and Psych Info. The focus was on Canadian Universities. We searched for "Canadian Universities" and used the list produced by Wikipedia. From this source, we looked at the total enrolment. We then searched for each university having at least 5000 students, accessed its main website, and, on the main page, searched for words such as "bullying", "harassment," policies" and "prevention" and combinations of these keywords. As well, we searched for "bullying" in the school most recent Academic Calendars (undergraduate and graduate) or students' handbooks and in the Frequently Asked Questions section. We only considered information provided in English. The search started in 2014 and concluded in 2017. The analysis was based solely on the information found on the Internet; the schools were not contacted to obtain additional materials. If one website was not working, or a page was not found, after several attempts and using different browsers, we excluded the respective information from the analysis. Thirty-nine institutions remained.

\section{RESULTS}

\section{(1) Information/Policies About Bullying}

Most of the Canadian colleges have on-line information about persecution. However, the amount of information provided differs significantly from an institution to another. Specifically, most universities define bullying and harassment and may discuss different types of each. They also give examples of harassment, show how people may be affected by harassment, and state their commitment to providing learning free of discrimination and intimidation. Sexual harassment and cyberbullying are often specifically addressed. Many schools define respect and respectful (positive) environment and emphasize the benefits of respectful working and learning. Some colleges discuss equity and human rights and may have equity and human rights services. Although some university used the terms bullying and harassment interchangeably, others present definitions of each sometimes following the law. For example, harassment was defined on the University of Western Ontario website as "engaging in a course of vexatious comment or conduct that is known or ought reasonably to be known to be unwelcomed." "This conduct must be related to one of the prohibited grounds such as race, sex, color, ancestry, place of birth, ethnic origin, marital status, same-sex partner status, sexual orientation, age, disability, citizenship, family status or religion" according to the Wilfrid Laurier University (2018). Bullying is defined by the University of Western Ontario to include: "ignoring or isolating an individual, humiliating a person in front of their peers, criticizing or blaming the target continually, belittling, degrading or demeaning the victim." Synonyms for bullying include, persecution, oppression, intimidation, and coercion.

Most of the universities have some discrimination and (personal) harassment policy and procedures. Policies define bullying and harassment, specify examples of each, explain how some people may be affected by such persecution, specify why is it important to deal with oppressive behaviors, complains and resolution, liability, appeals, and confidentiality. Occasionally it also describes what happens in the case of false complaints. Many colleges also have respectful learning and working environment statements, policies, and procedures. As well, some schools have principles of conduct, code of student behavior (conduct and misconduct), code (or charter) of student's rights and responsibilities, rights, and recourse of students table. Some universities have human rights and equity approaches and fair treatment policy. A few colleges have violence prevention strategies, personal security policy and conflict resolution services.

\section{(2) Advice and Help Available for Students}

Most of the universities offer to counsel victims. They also have advisors and peer advisers (support network, justice center) to help victims deal with persecution. Some have harassment and discrimination officers, human rights and 
diversity officers, and security office. Same colleges also provide consultants whereas some have assessors. Same schools direct individuals who face oppression to the students support services or student advocacy representative, whereas some also have volunteer mediators. The following offices, centers, services are available to students at Canadian Universities: Office of Student Conflict Resolution, Student Services Office, Centre for Human Rights, Sexual Harassment Education and Complaint Centre, Harassment, Discrimination Prevention and Conflict Resolution Services Office, Human Rights and Diversity Office, and Security and Emergency Services. These centers provide "an array of services and programs which include but are not limited to Walk Safe Escorts, Emergency Calling System, Emergency Medical Response, Safety Talks or Plans, and Self Defense Classes".

In terms of advice offered on-line to the individual being bullied, colleges tell victims " not to ignore bullying; to tell the harasser to stop; to talk to someone trusted about it; to remember that the person bullied is not to blame; to document what has happened; to try to keep a record of feelings about the event(s) and any emotional or physical effects noticed; to avoid being alone with the harasser; to get counseling and support, and to report crimes which include verbal harassment." Students that feel victims of cyber bullying are advised "not to ignore it; to call campus security, to inform service provider and local police; to avoid replying to messages from cyber bullies; to keep messages from cyber bullies as evidence, and to forward the offending e-mail and report to the human rights office."

Several educational institutions have documents detailing how to address bullying behaviors and how to assist victims. There can be a student's guide detailing what individuals need to do, what they shouldn't do, what to do if they or someone else behaves that way, and how they can help to create a respectful work and learning environment.

Regarding advice presented to everyone, several schools address it as follows: "Everyone can take action to help prevent discrimination and harassment. Treat others with respect, even if you don't agree with their values or opinions. Take action to resolve problems as early as possible. If you find someone's behavior problematic, let the person know how you feel and ask him or her to stop the behavior. Be sensitive to the impact that you have on others and be willing to alter or eliminate problematic behaviors. Consider apologizing if your actions have had a negative impact on someone". "What Students can do: see "Respectful University Community" as your own responsibility; know your rights; identify your feelings; identify and address inappropriate behavior/harassment. Speak out for someone else. Encourage others to participate as well. Take the initiative to talk to someone if it looks like they are under stress. Make a habit of positive feedback. Find a way that enables you to remember to give positive feedback. Be supportive of others. Role model respectful behaviors. Remember: what you do is more powerful than what you say".

Regarding harassment prevention, advice given by universities include, "accepting that NO means NO; become aware that your behavior, if unwelcome, can harass others, even if this was not your intention; clarify your understanding of differences among harassment, freedom of speech, academic freedom, and performance management; be aware that cultures different from your own may interpret actions differently than you do; and do not use power positions to initiate sexual relationships (even subtly). Instructions referring to bystander situations include, "object to harassment when you see or experience it; refuse to go along with harassment masked as humor or academic debate; choose not to use or share words, jokes and comments of a discriminatory nature that may adversely affect others; and make sure your attitudes and behavior don't condone harassing behavior in others". Finally, a call for education and support include, "circulate information to staff, students and faculty and encourage attendance at discrimination and harassment and cross-cultural training programs and offer support to anyone who is being harassed and help others modify inappropriate behavior."

Many colleges have educational programs that act to tackle bullying and harassment. Indeed, schools have educational sessions, programs, symposiums, presentations, talks, workshops, forums, or training courses for preventing and addressing persecution that may include reporting procedures as well as follow up. Educational presentations may also include professional actors portraying various scenarios, and may be shown to students, faculty, and staff. There is also research having as purpose to curb oppression conducted at some institutions. For example, at the university of Regina, a gender-based violence needs assessment report has been released (2017) (https://www.uregina.ca/external/communications/feature-stories/current/2017/03-30.html) and has nine recommendations that include developing survivor-focused protocols. 


\section{(3) Anti-Bullying Frameworks and Models}

A few universities developed, used, or discussed some theoretical approaches. For example, Mount Royal University (http://www.mtroyal.ca/cs/groups/public/documents/pdf/strengthsvsdeficitrb.pdf) discusses a "strength-based approach" in contrast to a "deficit-based approach" and also supplies examples of effective and less effective programs. Deficit-based strategies usually intervene after the problem is already there rather than working to stop it in the first place (Kretzmann \& Mcknight, 1993). Examples include "Zero-tolerance policies" (Fox, Elliot, Kerlikowske, Newman \& Christeson, 2000, p. 16) and the "Juvenile Crime Based Intervention Programs Such As 'Scared Straight'" (Petrosino, Turpin-Petrosino \& Buehler, 2003, p. 53). Strengths-based programs (considered more effective) involve a collaborative process between the persons accessing the services and those providing them, allowing them to work together to determine an outcome that draws on each individual's strengths and assets (Duncan $\&$ Miller, 2000). The strengths-based programs emphasize the quality of the relationship that develops between those providing support and those benefiting from it, creating the opportunity for individuals to be co-producers of services and support, instead of solely consumers (Morgan \& Ziglio, 2007). Examples of effective strengths-based programs include the "Olweus Bullying Prevention Program" (Greenberg, Domitrovich \& Bumbarger, 2001, p.14), "The Incredible Years" (Fox, Elliott, Kerlikowske, Newman, \& Christeson, 2000, p. 16), and "The Seattle Social Development Project" (Hawkins, Catalano, Morrison, O'Donnell, Abbott \& Day, 1992, as cited in Greenberg, Domitrovich \& Bumbarger, 2001). Some examples of strengths-based, community driven initiatives in Calgary are: "The Brentwood Community Garden" and "Patrick Airlie School Wall Mural Project" (Calgary Foundation, 2014. Based on these strategies, the Start Smart Stay Safe (S4) proposed model is a strengths-based plan aiming to enhance resiliency among children and their families by building on what they are doing well. S4 encourages a model of teaching where students, families, faculty and staff, counselors, and police, partner together to actively build positive relationships, create safe communities and prepare individuals for the challenges of a complex and diverse university environment and changing the world (Pattoni, 2012).

Saint Mary's University has a Health and Wellness Strategy that addresses bullying (www.smu.ca/webfiles/ SMUHealthandWellnessStrategy-1Sep11.docx). The plan proposes a holistic approach to health and wellness and gives a reference framework for the establishment of future programs. Three strategic themes are listed: University's Learning and Work Environment and Culture, Individual Opportunities and Personal Responsibility, and Academic Opportunities. Saint Mary's picture of health and wellness includes the following dimensions: intellectual, spiritual, financial, emotional, physical, social, occupations, and environmental.

The University of Guelph uses the S.A.F.E. program (Sexual Assault Free Environment), which promotes respectful relationships and addresses and educates on the issue of sexual assault and partner abuse (https://www.uoguelph.ca/studenthealthservices/wellness-centre/education-awareness/safe). The Wellness Education Centre presents seven dimensions of wellness as follows: emotional, environmental, intellectual, occupational, physical, social, and spiritual (https://www.uoguelph.ca/studenthealthservices/wellness-centre/seven-dimensionswellness).

\section{(4) Other Initiatives}

Less than half of the colleges we examined had any strategies that go beyond providing information on-line or listing people that can help in bullying circumstances (advisors, counselors). Some of the most popular initiatives seem to be the celebration of the anti-bullying day (pink shirt day), the bullying awareness week, the annual harassment prevention week, an anti-bullying and cyber bullying awareness week, and the National Anti-Bullying Awareness Month.

Vancouver Island University, Brock University, and Trent University run the Positive Space Campaign (https://www2.viu.ca/positivespace/Index.asp), (http://www.brocku.ca/safety/hrights-es), (http://www.trentu.ca/ ohrea/positive.php), which addresses discrimination and harassment based on sexual orientation and gender identity. Brock also has an anti-bullying campaign titled "Brock Educators Taking Action against Bullying" (http://brockeducatorsagainstbullying.weebly.com/), which has a pledge, a video, a blog, and pictures. The pledge states that "the educator will stand up to bullying whenever and wherever sees it, will help students deal with conflict, will be there for students whenever they need someone to talk to, will listen, will care, will encourage students to 
challenge stereotypes, will provide students with multiple perspectives, will encourage students to think critically of the media, will be aware that biases are taught, but they will not be taught by me, will lead by example, will set the standards with own behavior, will take responsibility for own actions, will encourage students to advocate for themselves and others, will help students to express themselves freely without fear, will encourage students to take pride in who they are, will help give students a voice for what they believe in, and will tell students it is their right to be whoever they want to be."

Several schools partnered with sports teams with the aim of tackling oppression. For example, the University of Toronto and the Varsity Blues program partnered with the Toronto Argonauts Football Club to host the annual Huddle Up Bullying Prevention Program that uses mentors' stories to encourage friendship and inclusion, and reduce or eradicate persecution. Similarly, Saint Mary's Football Huskies and Community Partners Initiate an Anti-Bullying Campaign and met with students to share an anti-bullying message through the "Bullies Never Win" program. Huskies football players and coaches delivered messages of respect and shared their own childhood experiences with bullying. Students had an opportunity to questions, see the Vanier Cup and take home a team poster with an anti-bullying message. Similarly, Saint Mary's University Women's Hockey has teamed up with "Be the game Inc." to help raise money for their "Kind Every Time" tour. The tour is traveling across Canada to take a stand against persecution. Minor Teams can win great prizes by joining the team in fighting bullying.

Other anti-bullying steps included:

- The University of Guelph's United Way campaign associated with the Red Cross which raises money to go towards anti-bullying programs among others;

- Ryerson University's initiative, where students at School of Media are tackling persecution through their transmedia project that includes a website, Twitter, Tumblr, videos, and a sticker campaign. The students have addressed the issue of standing by in the face of injustice by drawing attention to the role of the bystander in situations of bullying);

- The University of Windsor's video contest on the theme "Stand up to Bullying," organized by the University of Windsor Students' Alliance as part of its Anti-Bullying Week program.

- The University of Saskatchewan's PBS campaign titled "It's My Life" that defines bullying, identifies the victim and the target, provide advice on how to handle it, discuss the innocent bystanders, and talks about on-line bullying among others;

- Queen's University's Email Harassment STOPIT! (a joint initiative of the Human Rights Office, Campus Security, Information Technology Services, and the Dean of Student Affairs); and

- Man Up Against Violence and anti-bullying concerts at the University of Regina.

\section{(5) Relationship Between Preventive Measures and Incidence Figures}

Unfortunately, linking incidence figures with preventive measures is not possible in Canada at the moment due to the lack of data. Although 700 cases of sexual assault were reported at Canadian Universities between 2009 and 2013 (CBC, 2017) many are skeptical that the number can be so low; others have observed flaws in the study methodology; and others noticed the difficulty in drawing conclusions based on the data due to inconsistencies of collecting and reporting data. An update of 2014 numbers indicated that 16 schools reported no known situations of sexual assault at their institutions over the six-year period. The report also indicated that only a handful of Canadian colleges publicly share the number of sexual assaults reported on their campus. By comparison, the universities in the United States have the legal obligation to publicly disclose the number of these offences (CBC, 2017).

\section{CONCLUSION}

Although almost all universities in Canada considered in this review have anti-bullying policies and initiatives, their approaches vary widely. Numerous definitions of bullying, types of bullying, and ways to tackle bullying were identified. Some of the schools focus on sexual harassments, others focus on cyber bullying. Having very clear, consistent and easy to access information, policies, tools, and adequate investigation and response time is very important in maintaining a safe, respectful and bullying free campus. A multi-front approach to fight bullying and harassment would probably work better. Such plan should include not only information, policies and available 
resources (counselors, advisors), but also campus events (such as workshops, concerts, and pink days). Assessment reports such as that from the University of Regina can stipulate recommendations that can help focus existent efforts to stop sexual violence, improve the University's response, and ensure that students have a welcoming, safe place to learn and grow. Consistent with a strengths-based approach, the necessity for victim support has to be addressed and expanded to ensure good relationships developed between those providing support and those benefiting from it.

Further research into this topic could review how U.S. universities tackle bullying and harassment. Because of the legal requirement to publicly share the data, a future study on US universities could look at the effectiveness of preventive measures over time and what impact newer legislation has.

\section{ACKNOWLEDGEMENTS}

We would like to thank Desiree Bachynski for her work in the earlier stages of this research.

\section{AUTHOR BIOGRAPHIES}

Magdalena Cismaru studied consumer behavior and received a PhD in Marketing from the University of Houston. She is a Professor in the Faculty of Business Administration at the University of Regina. She is also Program Lead Research and Conexus Research Scholar in Financial Wellbeing. Her work in the area of social marketing and health decision making has been published widely in a variety of journals.

Romulus Cismaru is an Instructor and Program Lead International in the Faculty of Business Administration at the University of Regina. He previously published in journals such as the Journal of College Teaching and Learning, the International Review on Public and Nonprofit Marketing, and the Social Marketing Quarterly Journal.

\section{REFERENCES}

Aricak, O. T. (2009). Psychiatric symptomology as a predictor of cyberbullying among University Students. Eurasian Journal of Educational Research, 34, 167-184.

Brank, E. M., Hoetger, L. A., \& Hazen, K. P. (2012). Bullying. The Annual Review of Law and Social Science, 8, 213-30.

Bullying Laws in Australia (2014). No bullying.com. The movement against bullying. Retrieved from http://nobullying.com/bullying-laws-in-australia/

Bullying Prevention Resource Guide: Best Practices (2013). Selected program models. Retrieved from http://www.bullyingprevention.org/index.cfm/ID/10

Calgary Foundation (2014). A neighbourhood mural paints the picture of community. Retrieved from www.thecalgaryfoundation.org about_ourstories.htm

Canadian Red Cross (2016). Definitions of bullying and harassment. Retrieved from http://www.redcross.ca/how-wehelp/violence--bullying-and-abuse-prevention/educators/bullying-and-harassment-prevention/definitions-of-bullyingand-harassment

CBC (2017). New post-secondary sexual assault policies a start but fall short, experts say. Retrieved from http://www.cbc.ca/news/canada/new-post-secondary-sexual-assault-policies-a-start-but-fall-short-experts-say1.4078365

Colorosa, B. (2008). The bully, the bullied, and the bystander. New York, NY: Harper Collins Publishers.

Cowie, H. \& Myers, C-A (2014). Bullying amongst university students in the UK. The International Journal of Emotional Education, 1, 66-75.

Duncan, B. L. \& Miller, S. D. (2000). The client's theory of change: Consulting the client in the integrative process. Journal of Psychotherapy Integration, 10(2), 169-187.

Fox, A. J., Elliott, S., D, Kerlikowske, G., R, Newman, A., S, \& Christeson, W. (2000). Bullying prevention is crime prevention. Fight Crime: Invest in Kids, 1-24.

Greenberg, T. M., Domitrovich, C, \& Bumbarger, B. (2001). The prevention of mental disorders in school-aged children: Current state of the field. American Psychology Association, (4)1, 1 - 62.

Greengrass, K. (2013). Bullying in the 21st Century, Anti-Bullying Network. Retrieved from http://www.antibullying.net/unistudents.htm

Hawkins, J. D., Catalano, R. F., Morrison D., O'Donnell, J., Abbott, R., \& Day, L. (1992). The Seattle social development project: Effects of the first four years on protective factors and problem behaviors. In J. McCord \& R. Tremblay (Eds.), The prevention of antisocial behavior in children, (pp. 139-161). New York: Guilford Press. 
Johnson, J. L. (2000/2001). Learning communities and special efforts in the retention of university students: What works, what doesn't, and is the return worth the investment? Journal of College Student Retention, 219-238.

Karim, N. (2010). Bullying in Universities: It exists. The Independent. Retrieved from http://www.independent.co.uk/news/education/higher/bullying-in-universities-it-exists-1869267.html

Kretzmann, J. \& Mcknight, J. (1993). Building communities from the inside out: A path toward finding and mobilizing community assets. Illinois: ACTA Publications.

Lappalainen, C., Meriläinen, M., Puhakka, H., \& Sinkkonen, H-M. (2011). Bullying among university students - does it exist? Finnish Journal of Youth Research, 29(2), 64-80.

Murtaugh, P. A., Burns, L. D., \& Schuster, J. (1999). Predicting the retention of university students. Research at Higher Education, 40(3), 355-371.

Morgan, A., \& Ziglio, E. (2007). Revitalising the evidence base for public health: An assets model. International Journal of Health Promotion and Education, Supplement 2, 17-22.

Nandeshwar, A., Menzies, \& T., Nelson, A. (2011). Learning Patterns of University Student Retention. Expert Systems with Applications, 38, 14984-14996.

Olweus, D. (1996). Bullying at school: knowledge base and an effective intervention program. Ann. NY Acad. Sci. 794:265-76.

Pattoni, L. (2012). Strengths-based approaches for working with individuals. Retrieved from https://www.iriss.org.uk/resources/insights/strengths-based-approaches-working-individuals

Panjvani, L. (2013). An overview of anti-bullying legislation and alternatives in Canada. Retrieved from http://www.lawnow.org/an-overview-of-anti-bullying-legislation-and-alternatives-in-canada/

Petrosino, A., Turpin-Petrosino, C., \& Buehler, J. (2011). Scared straight and other juvenile awareness programs for preventing juvenile delinquency: A systematic review of the randomized experimental evidence. The ANNALS of the American Academy of Political and Social Science, 1-23.

Sacco, D., Silbaugh, K., Corredor, F., \& Doherty, D. (2012). An Overview of State Anti-Bullying Legislation and Other Related Laws. Retrieved from http://cyber.law.harvard.edu/sites/cyber.law.harvard.edu/files/State_Anti_bullying_Legislation_Overview_0.pdf

Sinkkonen, H.-M., Puhakka, H. \& Merilainen, M. (2014). Bullying at a university: Students' experiences of bullying. Studies in Higher Education, 39(1), 153-165.

Schenk, A. M., \& Fremouw, W. J. (2012). Prevalence, psychological impact, and coping of cyberbully victims among college students. Journal of School Violence, 11(1), 21-37.

Stevens, V., De Bourdeaudhuij, I. \& Van Oost, P. (2000). Bullying in Flemish schools: an evaluation of anti-bullying intervention in primary and secondary schools. British Journal of Educational Psychology, 70, 195-210.

Telegraph (2015a). One in three UK female students sexually assaulted or abused on campus. Retrieved from http://www.telegraph.co.uk/women/womens-life/11343380/Sexually-assault-1-in-3-UK-female-students-victim-oncampus.html

Telegraph (2015b). 'I was sexually assaulted by a fellow student - but my university did nothing'. Retrieved from http://www.telegraph.co.uk/women/womens-life/11340661/I-was-sexually-assaulted-by-a-fellow-student-but-myuniversity-did-nothing.html

Wang, J., Iannotti, R. J., \& Nansel, T. R. (2009). School bullying among adolescents in the United States: physical, verbal, relational, and cyber. J. Adolesc. Health 45, 368-375.

Wilfrid Laurier University (2018). Prevention of harassment and discrimination. Retrieved from https://www.wlu.ca/about/governance/assets/resources/6.1-prevention-of-harassment-and-discrimination.html

Zimbroff, J. (2007). Cultural Differences in perceptions of and responses to sexual harassment. Retrieved from http://scholarship.law.duke.edu/cgi/viewcontent.cgi?article=1140\&context=djglp 